\title{
Correspondence
}

\section{Reading for the Membership: the value of a core book}

\section{DeAR SIRS}

We note with interest the current debate on how to formulate cases for the MRCPsych examination. This is timely and long overdue. However, another area of concern to us is how trainees perform in the viva voce examination and more specifically how they 'read' for psychiatry. We have been holding 'mock' vivas for our candidates for the past four years and we have been struck at how often relatively simple questions concerning definitions, classification and basic epidemiology are mishandled by many of them. It is our belief that this is the result of faulty reading habits. The typical trainee coming up to the Membership examination will have read extensively, mostly from the College's Reading Lists. There will be much background information present, but at the viva candidates often stumble on such simple opening questions as 'How would you define obsessional neurosis?' or 'How common is schizophrenia?' Further elaboration of answers tends to show an unstructured organization of data.

To remedy this situation we would recommend trainees to get a short 'core' book at the outset of their careers, and over the next three years virtually learn this book off by heart. This would have several advantages:

1. At the start of one's career it would provide a good overview of psychiatry.

2. During the three years' basic training it is our impression that many trainees seem to lack an overall reading strategy. We feel their reading (at least 100 articles and chapters from the College's Reading Lists) should be built up around the core book. This is preferable to concentration on large textbooks of psychiatry which we feel should mostly be used for reference.

3. Coming close to the Membership it would avoid a not uncommon panic situation where a trainee says in despair: 'I've read a mountain of psychiatry, but I can't remember some of the simplest of things.'

4. At the Membership itself, as well as improving performance in the viva, the core book would also serve to improve performance in the essay paper. It would do this by providing a useful skeleton around which more extensive knowledge would be organized.

In short, we feel trainees should buy their core book at the start of their careers and not just as an aid to revision at the end.

AIdAN McGenNis BRIAN O'SHEA

St Brendan's Hospital Dublin

\section{Reassessing the MRCPsych}

DeAR SIRS

A number of correspondents recently made varied suggestions for the future of the MRCPsych Examination (Bulletin, October 1982, 6, 170-6) which ranged from abolishing all or part of it (Dr Chris Thompson) to producing a 'marathon' exam, both for examinees and examiners, of many case reports and scrutinized interviews (Dr Mark Aveline). As someone who took the exam only two years ago, utilizing the research option, and who this year had opportunity to be an examiner for the first time in Part I, Final MB, I should like to make a few comments about the recent suggestions in the Bulletin and some personal suggestions for change.

Unfortunately, the only views backed up by any kind of survey or statistics were those of Professor Trethowan, despite the fact that these were invited views and therefore to be of some weight. In fact $\mathrm{Dr}$ Thompson tells us the views he expresses are not his own but just points for debate. Surely what the College needs are people's real views so that it can consider these and make a decision-I think we all know what the various alternatives are.

My colleagues and I feel that the exam should not be a final end to training but a gate to pass through on the way. Dr Aveline seems to accept this view but expresses concern that trainees may only have a few years' experience before sitting the exam. Surely this exam, like the MRCP, can only test that one has acquired some of the basic facts relevant to one's practice? No exam, whether in psychiatry, general medicine or other subject, can test how you carry out your work and, indeed, I feel that much of the 'how' and the 'clinical skills' are learnt in higher training as a senior registrar. I believe that training in any area of medicine is in large part an apprenticeship, with knowledge of the necessary skills acquired gradually. These skills are perhaps best assessed by those with whom the trainee has worked. Recently, in Belfast, Professor Fenton has introduced a scheme of regular six-monthly assessments by consultants of trainees (and by trainees of individual training posts). Perhaps this type of scheme might be extended. Though general practitioners are required to keep a $\log$ book of cases, as Dr Thompson points out, these are only minimal notes which may provide the basis for discussing a particular type of problem during a viva. It strikes me that the production of detailed case histories, as Dr Aveline suggests, may only tell examiners that a person is a good notekeeper and has a good theoretical knowledge. The validity of this as a method to assess clinical skills has not been proved. To test theoretical knowledge the MCQ appears to be the best instrument, as Professor Trethowan points out.

Again, the suggestion of scrutinized interviews may produce extra anxiety in many examinees. The assessment of 